\title{
Feeding preferences and voluntary feed intake of dairy cows: Effect of conservation and harvest time of birdsfoot trefoil and chicory
}

\author{
D. Lombardi, ${ }^{*}$ E. Vasseur, ${ }^{*}$ R. Berthiaume, $\dagger$ T. J. DeVries, $\ddagger$ and R. Bergeron* ${ }^{* 1}$ \\ *Organic Dairy Research Centre, Université de Guelph, Campus d'Alfred, Alfred, ON, K0B 1A0 Canada \\ †Valacta, Ste-Anne-de-Bellevue, QC, H9X 3R4 Canada \\ ‡Department of Animal and Poultry Science, University of Guelph, Kemptville Campus, Kemptville, ON, K0G 1J0 Canada
}

\begin{abstract}
Bioactive forages contain compounds, such as tannins, that are active against pathogens. They have been successfully used in ruminants to control parasite infections. Because cattle may find bioactive forages unpalatable, it is of interest to know if an afternoon harvest time, which has been shown to increase the percentage of nonstructural carbohydrates (NSC), hence palatability, may mitigate this. The objectives of this study were to quantify voluntary intake and preference of dairy cows for 2 bioactive forages, harvested in the morning and evening, in addition to determining their time spent grazing on each forage species. The forage species evaluated were fresh chicory harvested at 0700 $\mathrm{h}$ (FCAM) and $1800 \mathrm{~h}$ (FCPM), fresh birdsfoot trefoil harvested at $0700 \mathrm{~h}$ (FBAM) and $1800 \mathrm{~h}$ (FBPM), birdsfoot trefoil baleage harvested the previous summer at $0700 \mathrm{~h}(\mathrm{BBAM})$ and at $1800 \mathrm{~h}(\mathrm{BBPM})$, and thirdcut alfalfa baleage harvested the previous summer and used as control (CON). Single forages were offered ad libitum in 30-min tests to 14 dairy cows to determine intake in a $7 \times 7$ Latin square (experiment 1). Every possible pair of forages (21 pairs) was then presented for a 30-min test to 8 different dairy cows, and feed intake was measured (experiment 2). Finally, time spent grazing on chicory and birdsfoot trefoil was measured on 12 dairy cows (experiment 3). The tests consisted of $2 \mathrm{~d}$ of restriction on 1 of the 2 fields for $1 \mathrm{~h}$, and $2 \mathrm{~d}$ of free-choice sessions $(1 \mathrm{~h})$ between the 2 fields adjacent to each other. Grazing time and location of the animals on the field was assessed through 2-min scan sampling. In experiment 1, the highest voluntary intakes were for CON, BBPM, and BBAM. In experiment 2, BBPM was preferentially consumed over all other forages followed by CON and BBAM. Multidimensional scaling showed that preference for BBPM, CON, and
\end{abstract}

Received February 5, 2015.

Accepted June 25, 2015.

${ }^{1}$ Corresponding author: rbergero@uoguelph.ca
BBAM in dimension 1 was positively associated with dry matter and nitrogen content, and negatively associated with hemicellulose and soluble N/total N. No relationships between dimension coordinates and any of the measured chemical composition variables could be found for the other 2 dimensions. In experiment 3, cows spent $71 \%$ of their time grazing in the birdsfoot trefoil field and $23 \%$ in the chicory field during the free-choice sessions. In conclusion, cows in the present experiments showed an overall preference toward baled forages compared with fresh forages, most notably toward birdsfoot trefoil baleage. Cow preference did not appear to be linked to harvest time (a.m. vs. p.m.).

Key words: feed preference, bioactive forage, chicory, birdsfoot trefoil, dairy cow

\section{INTRODUCTION}

Gastrointestinal infections are very common in dairy cows, and parasite burden typically increases with exposure to pasture (Vanderstichel et al., 2012). In dairy heifers, infection has been shown to reduce growth rate and delay sexual maturity (Mejía et al., 1999, 2009). Even though it is generally assumed that dairy cows can better deal with parasites than younger animals (Perri et al., 2011), infected and untreated animals have shown a reduced milk yield (Forbes et al., 2004).

Livestock producers rely on the routine use of anthelmintics to maintain animal health and productivity (Marley et al., 2006). Given the emergence of genetically resistant parasites to conventional anthelmintic treatments (Gilleard and Beech, 2007), and the restrictions imposed by organic dairy production standards on their use (Canadian General Standards Board, 2011), scientific evaluation of sustainable alternative treatments is needed for both conventional and organic pastured cows and heifers.

Bioactive forages, which contain secondary compounds that are active against pathogens (Athanasiadou and Kyriazakis, 2004), have been successfully used in ruminants to control parasite infections (Min et al., 2003). Dosing nematode-infested sheep with plant 
secondary compounds, such as condensed tannins, has been shown to reduce their fecal egg count (Athanasiadou et al., 2000), and grazing lambs on birdsfoot trefoil and chicory, forages rich in tannins, resulted in a reduced level of helminth parasites (Marley et al., 2003). In their review of temperate forages containing secondary compounds, Ramirez-Restrepo and Barry (2005) concluded that birdsfoot trefoil and chicory were among the most promising alternatives. More recently, we reported that heifers receiving a daily allowance of birdsfoot trefoil as a supplement to pasture did not show an increase over time in their fecal egg count, compared with heifers that did not receive a supplement (Shepley et al., 2015). Although it has been suggested that condensed tannins are the active compounds behind the anthelmintic effect of these alternative forages, other factors may be involved (Athanasiadou and Kyriazakis, 2004).

Condensed tannins also have the potential to prevent bloat and increase nitrogen utilization in ruminants (McMahon et al., 2000; Mueller-Harvey, 2006). However, high levels of condensed tannins in ruminant diets (Min et al., 2003) can have some disadvantages such as impairing rumen metabolism by affecting the mucosa in the digestive tract, and reducing the absorption and digestibility of fiber (Reed, 1995; Barry and McNabb, 1999). Additionally, condensed tannins are associated with a bitter taste (McMahon et al., 2000), which may serve as a warning to the animal on the potential negative effects of the forage (Marten, 1978).

As stated by Scharenberg et al. (2007), a high palatability of anthelmintic forages is necessary when offered from mixed grasslands, together with other forages, and even alone, to ensure a sufficient intake and rapid adaptation period. Most research on bioactive forages has focused on small ruminants (Min et al., 2003) that can tolerate higher bitterness than cattle (Bell, 1959). Because cattle may find bioactive forages unpalatable, it is of interest to determine if other plant characteristics may mitigate this. Forage total NSC are strongly correlated with palatability (Smit et al., 2006) and could possibly counteract the bitterness caused by condensed tannins. Timing of harvest or access to pasture is an important factor affecting forage NSC, as forages harvested in the later part of the day have a higher concentration of NSC than those harvested early in the morning (Morin et al., 2011, 2012). This occurs as a result of accumulation of NSC throughout the day, as the rate of photosynthesis exceeds the rate of respiration and carbon fixation (Burns et al., 2007). These diurnal variations in herbage chemical composition have been shown to cause changes in feeding behavior and DMI (Gregorini et al., 2008; Raggio et al., 2010).
The objectives of the present study were to (1) assess the voluntary intake and feeding rate of dairy cows for chicory and birdsfoot trefoil harvested in the morning and in the evening, (2) assess the preference or aversion of dairy cows for chicory and birdsfoot trefoil harvested in the morning and in the evening, as well as the relationship between the forage constituents and cow preference, and (3) determine time spent grazing on chicory or birdsfoot trefoil.

\section{MATERIALS AND METHODS}

Three experiments were conducted at the Organic Dairy Research Centre of the Université de GuelphCampus d'Alfred (Alfred, ON, Canada), following a protocol in agreement with the guidelines of the Canadian Council on Animal Care (CCAC, 2009), and approved by the University of Guelph Animal Care Committee. In experiment (Exp.) 1, voluntary intake for 7 forages were evaluated; in Exp. 2, the 7 forages were provided in pairs to assess cow preferences; and in Exp. 3, the time spent grazing on 2 forages was evaluated. For all experiments, cows were kept outdoors grazing and were brought in twice daily (approximately 0700 and $1700 \mathrm{~h}$ ) to a freestall barn to be milked. The experiments took place after morning milking and after cows received their daily ration of concentrate in the barn (ground wheat, micronized soybeans, salt, and minerals).

\section{Voluntary Intake (Exp. 1) and Preference (Exp. 2): Forages}

Seven forages were tested: fresh chicory (Cichorium intybus L.) cultivar Puna harvested at 0700 h (FCAM) and at $1800 \mathrm{~h}$ (FCPM), fresh birdsfoot trefoil ( $L o$ tus corniculatus L.) cultivar Bull harvested at $0700 \mathrm{~h}$ (FBAM) and at $1800 \mathrm{~h}$ (FBPM), birdsfoot trefoil baleage harvested at $0700 \mathrm{~h}(\mathbf{B B A M})$ and harvested at $1800 \mathrm{~h}$ in the summer of 2011 (BBPM), and baleage of third-cut alfalfa (Medicago sativa L.) cultivar Pickseed 2065MF harvested in the summer of 2011 (CON). All forages were grown at the same site. Chicory and birdsfoot trefoil were seeded in the summer of 2010, and alfalfa in 2008.

Fresh forage (FCAM, FCPM, FBAM, and FBPM) was harvested from fields that had been cut the previous summer. It was cut daily the day before serving with a sicklebar mower (John Deere 350, Moline, IL) to a stubble height between 2 to $5 \mathrm{~cm}$, and was manually collected into paper biodegradable bags $(8 \mathrm{~kg}$, Canadian Tire Co., Toronto, Ontario, Canada), which were stored in a refrigerator at $1^{\circ} \mathrm{C}$ overnight to preserve freshness. 
One bale of each birdsfoot trefoil baleage (BBAM and $\mathrm{BBPM})$ and alfalfa baleage (CON) was used per week. To reduce the week and day effect, a bale for each of these forages was opened the day before each experimental week and collected in paper biodegradable bags, which were stored in the refrigerator throughout the experimental week. On each experimental day, the required quantities of each of the forages were removed from the refrigerator at $0700 \mathrm{~h}$.

During an adaptation period conducted the week before the experiments, all animals were subjected, in their home pen, to ad libitum access for $30 \mathrm{~min}$ to each of the 6 novel forages to associate the postingestive feedback and taste (Pliner, 1982) produced by each of them. The control forage (third-cut alfalfa baleage) was not included in the adaptation period, as the cows received this forage, as a daily supplement, in a feeder located in the field. The adaptation period lasted $3 \mathrm{~d}$, providing one forage in the morning after milking and another in the afternoon. The order in which the forages were offered to each animal was randomized.

\section{Animals and Experimental Design}

In Exp. 1, 14 Holstein cows were tested for voluntary intake according to a replicated $7 \times 7$ Latin square design, with cows as columns and days as rows. The cows were randomly assigned to 1 of 2 groups. The first group $(\mathrm{n}=7$, mean $\pm \mathrm{SD}$ parity $=3 \pm 2, \mathrm{DIM}=285$ $\pm 134, \mathrm{BW}=661 \pm 51 \mathrm{~kg}$ ) was tested for voluntary intake from June 25 to July 1, 2012, and the second group $(\mathrm{n}=7$, mean $\pm \mathrm{SD}$ parity $=3 \pm 2, \mathrm{DIM}=202$ $\pm 84, \mathrm{BW}=606 \pm 28 \mathrm{~kg}$ ) from July 2 to July 8, 2012 . One of 7 forages was presented to each cow per day over a period of $7 \mathrm{~d}$. Experimental forages were provided at the manger to all 7 cows at $0930 \mathrm{~h}$. The cows were head locked with visual access to other cows but separated with a white plastic divider $(91.5 \mathrm{~cm}$ in length $\times 40.5$ $\mathrm{cm}$ in height) and had ad libitum access to each forage for $30 \mathrm{~min}$. The weight of the forage was determined before and after feeding.

In Exp. 2, 8 Holstein cows (different from Exp. 1, mean \pm SD parity $=2 \pm 1$, mean DIM $=177 \pm 113$, mean $\mathrm{BW}=598 \pm 190 \mathrm{~kg}$ ) were tested from June 25 to July 15, 2012. Each possible pair of the 7 forages (21 pairs) was presented to each cow over a period of $21 \mathrm{~d}$ following a method adapted from Buntinx et al. (1997). One forage pair was presented each day at $1045 \mathrm{~h}$ at the manger where the 2 forages were separated by a white plastic divider. The cows were locked in headlocks with visual access to other cows, and had ad libitum access to each forage pair for $30 \mathrm{~min}$. The weight of both forages was determined before and after feeding. The order in which the forages were presented was random- ized, as well as the right-left position of the forages. All cows were tested simultaneously for each experiment in their home pen.

\section{Forage Analysis and Sorting}

Herbage samples for each species and harvest time (Exp. 1 and Exp. 2) were taken daily and frozen at $-15^{\circ} \mathrm{C}$ in plastic bags. The samples were then pooled weekly and subsampled to determine DM and chemical composition. Intake was measured based on the amount of forage offered and the amount of forage left over by each animal calculated as DM per minute and as fed per minute. In addition, samples were also taken for all fresh forages before and after feeding to determine sorting behavior. These were separated in 2 fractions: bioactive forage and other. The percent DM amount of the bioactive fraction in the offered forage and that in the leftover forage was obtained. The following equation was used to determine sorting behavior [\% DM: (bioactive fraction in offered forage/bioactive fraction in leftover forage) $\times 100]$. Values equal to $100 \%$ indicated no sorting, $<100 \%$ indicated selective refusals (sorting against), and $>100 \%$ indicated preferential consumption (sorting for; following Greter and DeVries, 2011). Baleages were not sampled for sorting behavior because it was not possible to separate these into fractions. Samples used to determine sorting behavior were dried in a forced-air oven (LC-18 Asphalt Oven, Thermo Scientific, Dubuque, IA) at $105^{\circ} \mathrm{C}$ for 6 to $10 \mathrm{~h}$. Other herbage samples were dried in a forcedair oven at $55^{\circ} \mathrm{C}$ for $48 \mathrm{~h}$ and then ground through a 1-mm screen (Wiley Mill, Arthur H. Thomas Co., Philadelphia, PA) to determine DM and were sent for chemical analysis to Agriculture and Agri-Food Canada (Lennoxville, QC, Canada).

Samples were individually analyzed for total ethanol soluble carbohydrates and starch according to Hall et al. (1999). Total NSC was obtained by adding TESC plus starch. Samples were also analyzed for analytical DM (method 930.15; AOAC International, 2006) and ash with a thermogravimetric analyzer (model TGA601, Leco Corporation, St. Joseph, MI); total N, NDIN, and ADIN using micro-Kjeldahl analysis (Kjeltec 2400 instrument, Foss Analytical, Hillerod, Denmark; method 976.06; AOAC International, 2006); soluble N with a borate phosphate buffer (Licitra et al., 1996); $\mathrm{NDF}, \mathrm{ADF}$, and ADL with the Ankom ${ }^{200}$ fiber analyzer (Ankom Technology, Fairport, NY) using heat-stable Q-amylase and sodium sulfite (Van Soest et al., 1991); and ether extract with a Soxtec system HT6 apparatus (Tecator, Fisher Scientific, Montreal, Canada). Total condensed tannins were determined by a butanol-HCl method (Grabber, 2008). 


\section{Grazing Behavior (Exp. 3)}

Twelve Holsteins (mean \pm SD parity $=2 \pm 1$; DIM $=$ $180 \pm 112$ ) from the previous 2 experiments were used to ensure that pasture species were not novel to them. The cows were separated into 2 groups of 6 cows and subjected to a 4-d cycle preference test from August 7 to 10, 2012. The no-choice phase (d 1 and 2) consisted of each group restricted from 0900 to $1000 \mathrm{~h}$ to either a chicory or a birdsfoot field on $\mathrm{d} 1$, and the alternative field (birdsfoot or chicory) on d 2. The free-choice days (d 3 and 4) consisted of all cows having free access to both fields located adjacent to each other. Each day, the cows entered a new plot of either the chicory field on the left or the birdsfoot trefoil field on the right. Each plot was of equivalent surface $\left(309 \mathrm{~m}^{2}\right)$, which ensured that all cows received 10 times their voluntary intake. Both fields were seeded in the summer of 2010 and were the regrowth from experiments 1 and 2 . The point of entry to the fields was located in between both plots and remained this way throughout. One water trough was located on each plot at the same point for each field. On all experimental days, the following behaviors in both fields were scan sampled every $2 \mathrm{~min}$ by one trained observer: grazing (standing immobile or walking with head down) or other. In addition, for the free-choice days, the cow's location on the field (chicory or birdsfoot trefoil plots) was also recorded in the same manner. The observer was positioned at the entrance between the 2 fields. The cows had previously been accustomed for 2 mo to grazing in groups and in the presence of the observer. The time spent grazing on each forage species was determined during the freechoice days. Additionally, the percentage of time spent grazing when the animals were forced to remain in one field was assessed. Forage samples were collected by random sampling of 10 locations on both plots pre- and postfeeding to determine botanical composition and sorting behavior.

\section{Statistics}

Feed intake data (Exp. 1) were analyzed with the MIXED procedure of SAS Institute Inc. (2008). The model included the fixed effects of treatment, day within square and square, and the random effect of cow within square. Normality was tested with the UNIVARIATE procedure of SAS. The sorting data distribution was abnormal for Exp. 1, and therefore, a natural logarithm was performed to normalize the data.

Preference data (Exp. 2) were analyzed by the multidimensional scaling (MDS) procedure of SAS. For MDS, the differences in preference between a pair of forages was expressed by subtracting the amount of the least preferred forage from the most preferred forage and dividing by the sum of the 2 intakes (Buntinx et al., 1997; Burns et al., 2001). Thus, values for each pair combination ranged between 0 and 1 , and preference was expressed numerically as a relative difference or distance. If the cow consumed equal quantities of the forages provided in the pair, then the difference ratio was equal to 0 and no preference or distance between the forages was expressed. If the cow had a strong preference and only one of the pair was consumed, then the difference ratio was equal to one and the forages were judged to be very different (Buntinx et al., 1997). For each cow, the ratios were arranged in a matrix representing all possible pairwise combinations of the forage treatments, without specifying which forage of the combination was preferred. This resulted in a triangular (symmetrical) matrix of ratios for each cow (Supplemental Table S1; http://dx.doi.org/10.3168/ jds.2015-9427). The set of matrices were analyzed in 2, 3 , and 4 dimensions with the MDS procedure of SAS. The MDS procedure estimates coordinates for a set of objects in a space with a predefined dimension (SAS Institute Inc., 2008). In the present situation, forages with similar coordinates in the dimensional space were modeled as similar in preference, whereas coordinates far apart in the dimensional space were modeled as different in preference. Pearson correlation analyses were performed between chemical analysis variables and coordinates for each forage, using the PROC CORR procedure of SAS.

Finally, a paired $t$-test was used within the UNIVARIATE procedure to analyze at each phase (no-choice and free-choice) the differences in percentage of time spent grazing chicory versus birdsfoot trefoil in Exp. 3 .

\section{RESULTS}

\section{Voluntary Intake (Exp. 1)}

The results for cow voluntary intake for each forage species (chemical composition reported in Table 1) show substantial variation in voluntary intake between fresh and fermented forages (Figure 1). On an as-fed basis, CON and BBPM were consumed in higher amounts $(P<0.01)$ than the other forages. However, on a DM basis, all fermented forages including BBAM were consumed in higher amount $(P<0.001)$ than the fresh forage. The BBAM and BBPM were different from each other on an as-fed basis $(P<0.01)$ and tended to differ on a DM basis $(P=0.08)$. No differences $(P>0.1)$ were found in voluntary intake between harvest times of fresh bioactive forages (FCAM, FCPM, FBAM, and FBPM). 
Fresh forages had an equivalent botanical composition of $65 \%$ chicory or birdsfoot trefoil, and $35 \%$ of mixed species. No treatment $(P=0.60)$ or time $(P=$ 0.62 ) effects were observed on sorting behavior. The average sorting values for fresh forages were 100.2, 79.7, 108.9, and $114.6 \%$ for FCAM, FCPM, FBAM, and FBPM $(\mathrm{SE}=19.15)$, respectively.

\section{Preference for Paired Forage (Exp. 2)}

The intakes for the 21 pairs of forages averaged over 8 cows are illustrated in Figure 2. Total intakes ranged widely with BBPM combinations higher than any other combination followed by CON and BBAM combinations. The MDS revealed that selection between forages was associated with 3 dimensions $(P<0.001)$. Dimension 1 was estimated to have the most weight (0.64), followed by dimension $2(0.15)$ and dimension $3(0.07)$. The BBPM was used as a positive control, as it was always chosen in a pair and also had the highest mean voluntary intake during the paired tests, and the signs of the 3 dimensions were set so that BBPM was positive in all dimensions.

Coordinates obtained for each forage, in 2 of the 3 dimensions, are presented in Figure 3. A positive rank of forage represents preference, whereas a negative rank indicates avoidance. In dimension 1 the forages could be divided into 2 groups, with the 3 most preferred forages (BBPM, CON, BBAM) at one end of the axis, and the remaining 4 at the opposite end. The correlation analysis in dimension 1 revealed that forage coordinates were positively associated with $\mathrm{DM}(\mathrm{r}=0.95, P$ $<0.01)$ and total $\mathrm{N}(\mathrm{r}=0.87, P<0.05)$, reflecting the higher DM and nitrogen contents of BBAM, BBPM, and CON forages (Table 1). In addition, dimension 1 coordinates were negatively associated with 2 compositional variables, which were hemicellulose $(\mathrm{r}=-0.96$, $P<0.001)$ and soluble $\mathrm{N} /$ total $\mathrm{N}(\mathrm{r}=-0.92, P<$ 0.01 ), the values for these 2 compositional variables being lower for BBPM, CON, and BBAM compared with the other forages (Table 1 ). In dimensions 2 and 3 , no associations could be found between forage coordinates and chemical composition.

\section{Grazing Behavior (Exp. 3)}

When restricted to one field, cows spent on average 92 and $89 \%$ of their time grazing birdsfoot trefoil and chicory, respectively, with no difference between forages $(P>0.1)$. When cows had the choice between 2 fields, they spent on average 71 and $23 \%$ of their time grazing on birdsfoot trefoil and chicory, respectively $(P$ $<0.05$ ). The botanical compositions were $69 \%$ chicory and $44 \%$ birdsfoot trefoil in the chicory and birdsfoot

Table 1. Chemical composition of experimental forages used in experiments 1 and $2^{1}$

\begin{tabular}{|c|c|c|c|c|c|c|c|}
\hline Item & FBAM & FBPM & FCAM & FCPM & BBAM & BBPM & $\mathrm{CON}$ \\
\hline$\overline{\mathrm{DM}^{2}}$ & 25.33 & 27.77 & 23.14 & 25.16 & 50.71 & 42.30 & 48.85 \\
\hline $\mathrm{Ash}^{2}$ & 5.82 & 5.40 & 9.49 & 8.65 & 7.07 & 7.17 & 10.41 \\
\hline $\mathrm{ADF}^{2}$ & 43.86 & 45.84 & 38.79 & 39.30 & 42.83 & 42.99 & 36.36 \\
\hline ADIN & 0.22 & 0.22 & 0.25 & 0.26 & 0.23 & 0.21 & 0.29 \\
\hline $\mathrm{NDF}^{2}$ & 56.79 & 57.42 & 52.32 & 50.74 & 50.62 & 50.34 & 43.22 \\
\hline NDIN & 0.31 & 0.30 & 0.51 & 0.51 & 0.23 & 0.23 & 0.38 \\
\hline Hemicellulose $\mathrm{e}^{2,3}$ & 12.93 & 11.58 & 13.54 & 11.44 & 7.78 & 7.34 & 6.86 \\
\hline Cellulose $\mathrm{e}^{2,4}$ & 34.17 & 35.98 & 31.63 & 32.51 & 34.19 & 34.74 & 29.74 \\
\hline $\mathrm{ADL}^{2}$ & 9.69 & 9.85 & 7.16 & 6.80 & 8.64 & 8.26 & 6.62 \\
\hline $\mathrm{N}_{\text {total }}{ }^{2}$ & 1.85 & 1.86 & 1.33 & 1.26 & 2.24 & 2.34 & 2.73 \\
\hline Soluble $\mathrm{N}^{2}$ & 1.07 & 1.20 & 1.04 & 0.93 & 0.88 & 0.89 & 1.25 \\
\hline Soluble N/N total ${ }^{2}$ & 0.58 & 0.64 & 0.78 & 0.74 & 0.39 & 0.38 & 0.46 \\
\hline $\mathrm{ADIN} / \mathrm{N}$ total $^{2}$ & 0.12 & 0.12 & 0.19 & 0.21 & 0.10 & 0.09 & 0.11 \\
\hline $\mathrm{NDIN} / \mathrm{N}$ total $^{2}$ & 0.17 & 0.16 & 0.38 & 0.40 & 0.10 & 0.10 & 0.14 \\
\hline $\mathrm{TESC}^{2,5}$ & 6.35 & 9.24 & 9.07 & 9.70 & 7.88 & 6.86 & 6.91 \\
\hline Starch $^{2}$ & 0.34 & 1.10 & 1.04 & 1.60 & 0.51 & 0.46 & 0.45 \\
\hline $\mathrm{NSC}^{2,6}$ & 6.69 & 10.35 & 10.11 & 11.30 & 8.38 & 7.32 & 7.36 \\
\hline Ether extract ${ }^{2}$ & 1.19 & 1.19 & 1.85 & 1.94 & 1.79 & 1.48 & 2.42 \\
\hline Tannins ${ }^{2,7}$ & 0.34 & 0.30 & 0.15 & 0.20 & - & - & - \\
\hline
\end{tabular}

${ }^{1}$ Each value is the mean of 3 daily samples pooled weekly. Values are provided in $\%$ of DM, except for DM and analytical DM. FBAM, FBPM $=$ fresh birdsfoot trefoil harvested in the a.m. and p.m., respectively; FCAM and FCPM = fresh chicory harvested in a.m. and p.m., respectively; $\mathrm{BBAM}, \mathrm{BBPM}=$ birdsfoot trefoil baleage harvested in the a.m. and p.m., respectively; CON = alfalfa control baleage.

${ }^{2}$ Variables used for correlations with MDS dimensions.

${ }^{3} \mathrm{NDF}-\mathrm{ADF}$

${ }^{4} \mathrm{ADF}-\mathrm{ADL}$.

${ }^{5}$ Total ethanol-soluble carbohydrates.

${ }^{6} \mathrm{NSC}=\mathrm{TESC}+$ starch.

${ }^{7}$ Was not measured in baled forages. 


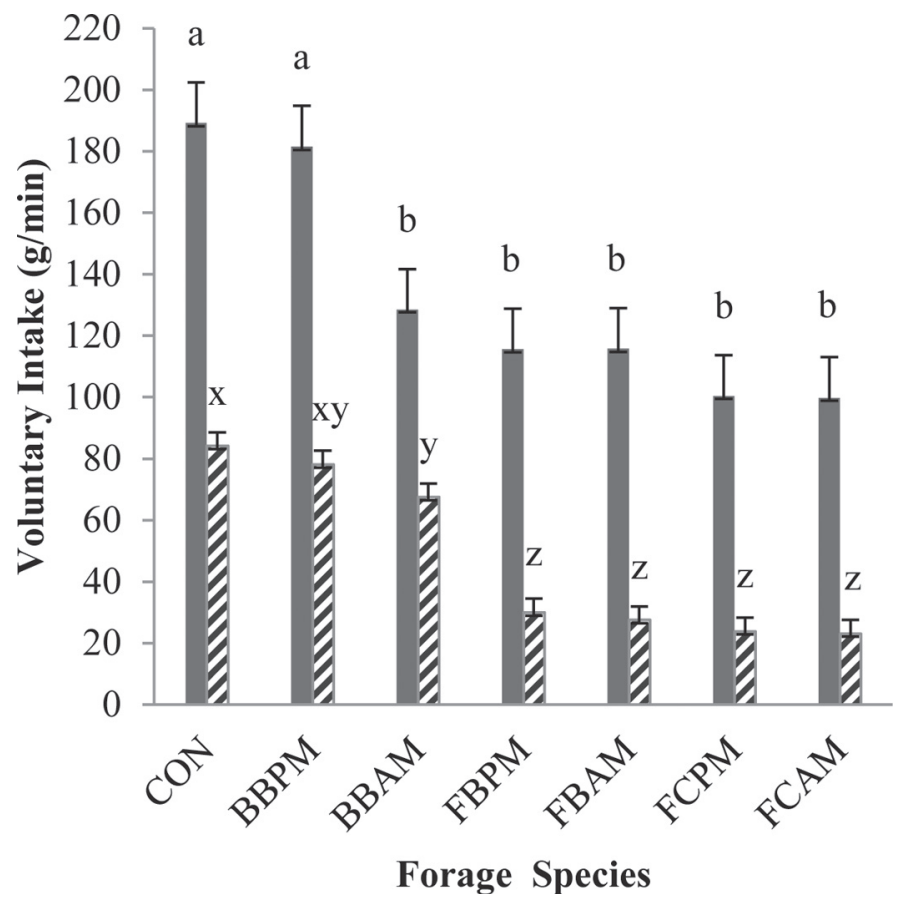

Figure 1. Least squares mean $( \pm \mathrm{SE})$ of voluntary intake of cows fed 7 types of forage during 30-min tests in experiment 1 . Solid bars represent voluntary intake in grams as fed per min ${ }^{\mathrm{a}, \mathrm{b}} \mathrm{LSM}$ with different letters are different at $P \leq 0.05)$. Patterned bars represent voluntary intake in grams of DM per minute $\left({ }^{\mathrm{x}-\mathrm{L}} \mathrm{LSM}\right.$ with different letters are different at $P \leq 0.05)$. FCAM and FCPM $=$ fresh chicory harvested in a.m. and p.m., respectively; FBAM, FBPM = fresh birdsfoot trefoil harvested in the a.m. and p.m., respectively; BBAM, BBPM = birdsfoot trefoil baleage harvested in the a.m. and p.m., respectively; $\mathrm{CON}=$ alfalfa control baleage .

trefoil fields, respectively. Both forages were preferentially sorted $(>100 \%)$, with an average sorting of 113 and $124 \%$ for chicory and birdsfoot trefoil, respectively.

\section{DISCUSSION}

In this study, we determined the short-term voluntary intake and preference of dairy cows for 2 forage species rich in secondary compounds in relation to harvest time. When offered as a single option, baled forages were voluntarily consumed in higher quantities than the fresh forages. Voluntary intakes for the same forages offered in pairs were consistent with intakes when fed on their own. Birdsfoot trefoil baleages and the control alfalfa baleage were always preferred over fresh forages, and BBPM was determined as the most preferred forage. These findings do not entirely support the assumption that forage species high in secondary compounds reduce voluntary intake because of their bitter taste (Reed, 1995), at least not when offered as baleage. Processing, such as ensiling, has a major effect on structure and chemistry of forages and may change the biological activity of their secondary compounds, as a result of reactions with other plant molecules and fermentation products (Scharenberg et al., 2007). In a study by Minnee et al. (2002), total condensed tannins in birdsfoot trefoil were not affected by the ensiling process, but free condensed tannins were reduced. This may explain the improvement in palatability of baleage in the current study, although in a study with sheep, Scharenberg et al. (2007) did not report an improved palatability for ensiled compared with dried birdsfoot trefoil.

Condensed tannin composition could not be obtained for baled forages in the present experiment and further research is needed to confirm this. Nevertheless, condensed tannins did not appear to play a major role in fresh forage selection, because chicory and birdsfoot trefoil fresh forages were equally consumed when offered as a single option, despite a numerically higher condensed tannin content in birdsfoot trefoil. It should be noted, however, that condensed tannin percentages in fresh birdsfoot trefoil $(0.30-0.34 \%)$ were relatively low compared with other studies (4.6\%: Jackson et al., 1996; 2.9\%: Minnee et al., 2002) and may have been insufficient to negatively affect palatability. In contrast, the percentages of condensed tannins measured in chicory $(0.15-0.20 \%)$ were similar to the value $(0.17 \%)$ reported by Jackson et al. (1996). However, condensed tannin percentages for both chicory and birdsfoot trefoil were below the level $(5.5 \%)$ reported to reduce voluntary feed intake in sheep (Waghorn et al., 1994). This suggests that other secondary plant compounds in chicory could be modulating its palatability in cattle. Sesquiterpene lactones, for instance, are known to be bitter and to reduce chicory herbage acceptance in ruminants (Foster et al., 2006). Cows in the present study spent more time grazing in the birdsfoot trefoil plot when offered free choice between birdsfoot trefoil and chicory. This is consistent with the voluntary intake measured with freshly cut forages, even though the numerical difference between fresh birdsfoot trefoil and chicory was not significant. Horadagoda et al. (2009) compared grazing preferences in dairy cows for 14 forage species, and although they did not test birdsfoot trefoil, they reported that chicory had one of the lowest palatabilities. In addition, cows in the present study may have found chicory more difficult to harvest and masticate, as observed by Gregorini et al. (2013), which may have affected their time spent grazing. Many other physical factors, such as sward height and bulk density, are known to affect grazing behavior in cattle (Griffiths et al., 2003), but were not measured in the present experiment.

Contrary to our hypothesis, harvest time did not affect forage preferences in the present study. When 
they were provided as a single option, no differences in voluntary intake were found between fresh birdsfoot trefoil and chicory harvested in the morning or the afternoon, despite higher soluble carbohydrate and NSC contents in the afternoon, especially in the case of birdsfoot trefoil. This contrasts with the study of Smit et al. (2006) who reported a strong correlation between water-soluble carbohydrates and palatability. The NSC of a plant increases palatability, as dairy cows prefer sweet taste to all other tastes (Jones and Roberts, 1991; Nombekela et al., 1994). Findings by Horadagoda et al. (2009) also determined that NSC concentration explained more variation in cow preference than any other characteristic. It is possible that NSC differences between forages harvested in the morning versus the afternoon were not sufficiently pronounced, particularly for chicory, to have a significant effect on palatability.

The MDS analysis revealed that in dimension 1, the preference for birdsfoot trefoil and control baleages over fresh birdsfoot trefoil and chicory was associated with 4 main forage characteristics, the first one being the DM content. Because differences in DM were confounded with the conservation method, it cannot be concluded that DM content per se positively affected preferences in the present experiment. The fact that baleages were consumed more than fresh forages contrasts with previous studies in cows reporting a higher DMI for fresh forage or hay compared with same forage preserved as silage (Nicholson et al., 1992). However, the intake limiting effect of silage has been linked to the quantity and quality of fermentation products (Allen, 2000), which are present at a lower concentration in baleage. Waldo and Jorgensen (1981) did not report voluntary intake differences between hay and silage, when silage dry matter was $40 \%$ or higher. Interestingly, when hay, haylage, and silage of the same grass crop were simultaneously offered to horses, silage was the most preferred forage, hay was the least preferred, and haylage was intermediate (Müller and Udén, 2007).

The second characteristic explaining forage preference was hemicellulose content. Preferred forages contained a lower percentage of hemicellulose, which could be explained by their earlier vegetative stage at the time of harvest (Kirchhof et al., 2010). In cattle,

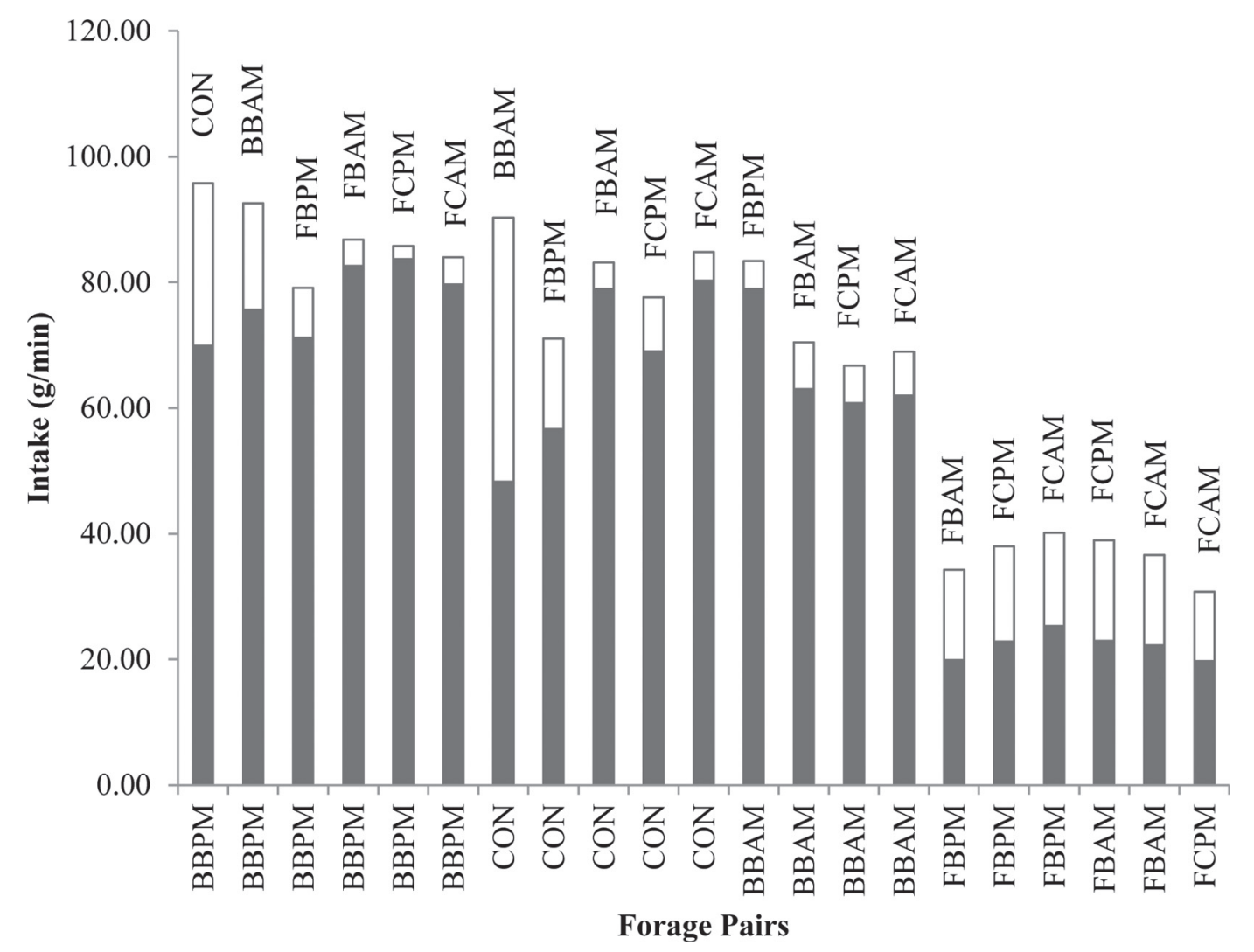

Figure 2. Mean intakes (g/min) on a DM basis for the 21 forage combinations from experiment 2. The lower portion of each bar (solid) indicates the intake of the forage listed under the bar on the horizontal axis. The upper bar (open) indicates the intake of the forage listed vertically at the top of each bar. FCAM and FCPM = fresh chicory harvested in a.m. and p.m., respectively; FBAM, FBPM = fresh birdsfoot trefoil harvested in the a.m. and p.m., respectively; BBAM, BBPM = birdsfoot trefoil baleage harvested in the a.m. and p.m., respectively; CON = alfalfa control baleage. 


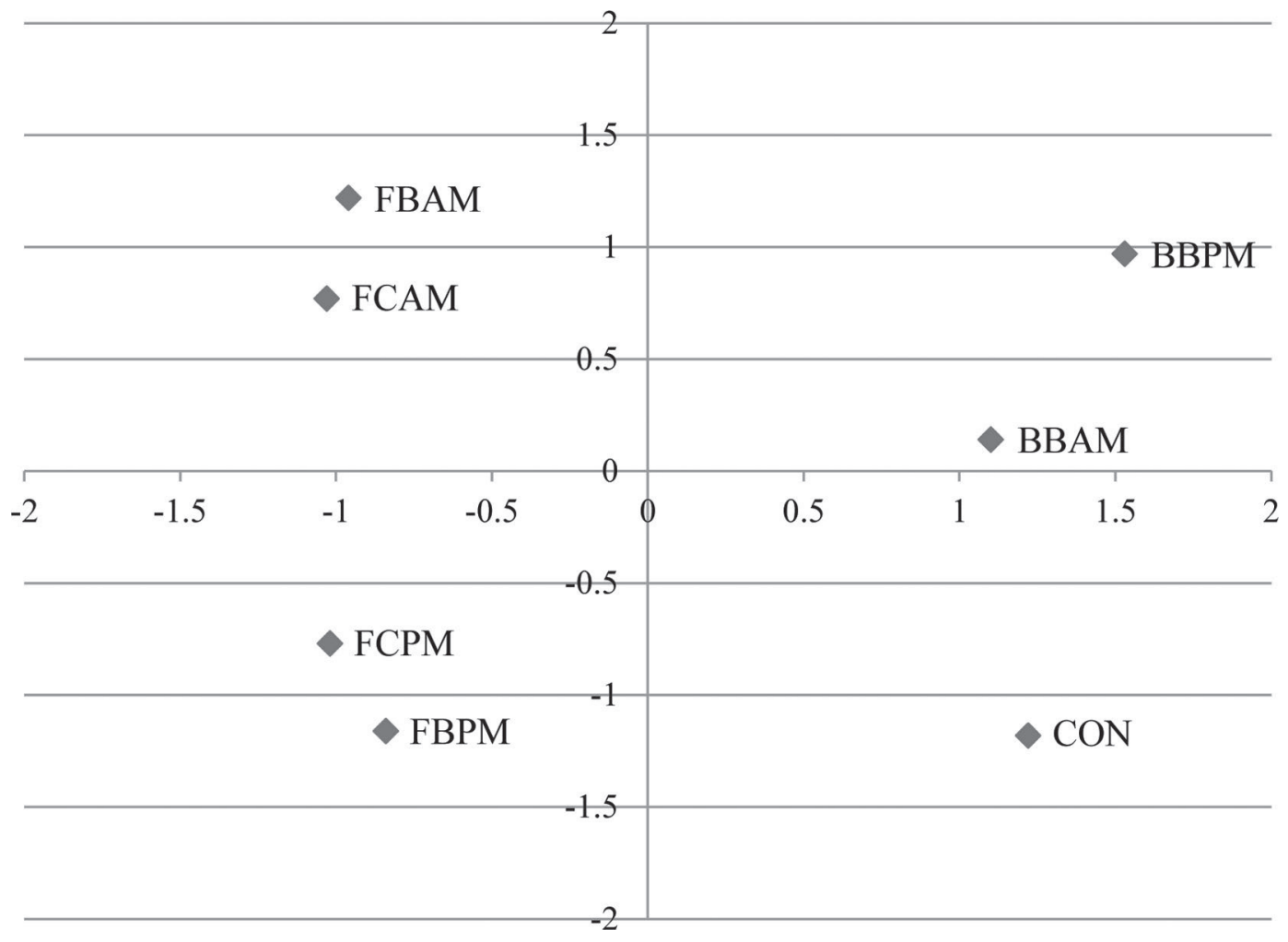

Figure 3. Coordinates obtained for 2 dimensions of the 3-dimensional solution to the forage preferences among dairy cattle in experiment 2. FCAM and FCPM = fresh chicory harvested in a.m. and p.m., respectively; FBAM, FBPM = fresh birdsfoot trefoil harvested in the a.m. and p.m., respectively; BBAM, BBPM = birdsfoot trefoil baleage harvested in the a.m. and p.m., respectively; CON = alfalfa control baleage.

voluntary intake and eating rate have been reported to be negatively associated with NDF and ADF content of forages (McLeod and Smith, 1989). Similarly, Horadagoda et al. (2009) reported a negative relationship between NDF and cow preference for grass and legume species. A multidimensional scaling study in sheep and goat exposed to a variety of tall fescue hays also reported negative associations between preference and fiber fractions, although not specifically with the hemicellulose portion (Burns et al., 2001).

Finally, preference in the present study was also associated with forage nitrogen content. A positive correlation was found for total nitrogen, which is in line with the reported increased selection of a high protein silage concentrate mixture by dairy cows in a choice experiment (Tolkamp et al., 1998). However, if soluble $\mathrm{N}$ is in excess of fermentable energy in the rumen, it will be converted into ammonia, which will be absorbed through the rumen wall. Excessive ammonia in circulation is toxic to the cow. Ammonia is detoxified in the liver through the synthesis of urea, which is excreted via the urine and milk or recycled via saliva. This process is energetically expensive. Hence, several authors have found that animal performance improved as $\mathrm{N}$ solubility in the diet decreased (Givens et al., 2000).
This could explain why the correlation between preference and soluble $\mathrm{N} / \mathrm{N}$ total was negative, meaning that the most preferred forages contained a lower proportion of soluble $\mathrm{N}$.

In dimensions 2 and 3, forage coordinates could not be associated with chemical composition measured, suggesting that preferences were likely linked to characteristics that were not analyzed. Because plant morphological differences were not minimized through chopping, cues affecting preference could be compositional or morphological (Burns et al., 2001).

\section{CONCLUSIONS}

Our results show that palatability of anthelmintic forages is not affected by harvest time of day, but may be improved by the ensiling process. Because differences in harvest time resulting in fiber and protein content differences between fresh and baled forages may partly explain the results, more research comparing forages of equivalent composition is needed. In the field, cows spent more time grazing on birdsfoot trefoil, compared with chicory, but grazing intake of each species remains to be established. Further work is also needed to better understand the chemical and physical factors underly- 
ing the observed preferences and to test the anthelmintic effects of the forages served fresh, ensiled, and in the field.

\section{ACKNOWLEDGMENTS}

This work was funded by a grant from the Ontario Ministry of Agriculture, Food and Rural Affairs (Guelph, Ontario, Canada) through the Summer Experience program, a grant from Conseil de la Coopération de l'Ontario (Ottawa, Ontario, Canada) through the Young Canada Works program, and a grant from the Agricultural Adaptation Council (Guelph, Ontario, Canada) and Dairy Farmers of Ontario (Mississauga, Ontario, Canada) through the CanAdvance program. We thank David Jeker (Université Laval, Québec, Québec, Canada) for data collection. We thank Serge Courchesne and barn staff from the Organic Dairy Research Centre of the Université de Guelph-Campus d'Alfred for their help with the animals.

\section{REFERENCES}

Allen, M. S. 2000. Effects of diet on short-term regulation of feed intake by lactating dairy cattle. J. Dairy Sci. 83:1598-1624.

AOAC International. 2006. Official Methods of Analyses. 18th ed. AOAC Int., Gaithersburg, MD.

Athanasiadou, S., and I. Kyriazakis. 2004. Plant secondary metabolites: Antiparasitic effects and their role in ruminant production systems. Proc. Nutr. Soc. 63:631-639.

Athanasiadou, S., I. Kyriazakis, F. Jackson, and R. L. Coop. 2000 Consequences of long-term feeding with condensed tannins on sheep parasitised with Trichostrongylus colubriformis. Int. J. Parasitol. 30:1025-1033.

Barry, T. N., and W. C. McNabb. 1999. The implications of condensed tannins on the nutritive value of temperate forages fed to ruminants. Br. J. Nutr. 81:263-272.

Bell, F. R. 1959. Preference thresholds for taste discrimination in goats. J. Agric. Sci. 52:125-128.

Buntinx, S. E., K. R. Pond, D. S. Fisher, and J. C. Burns. 1997. The utilization of multidimensional scaling to identify forage characteristics associated with preferences in sheep. J. Anim. Sci. 75:16411650.

Burns, J. C., D. S. Fisher, and H. F. Mayland. 2001. Preference by sheep and goats among hay of eight tall fescue cultivars. J. Anim. Sci. 79:213-224.

Burns, J. C., D. S. Fisher, and H. F. Mayland. 2007. Diurnal shifts in nutritive value of alfalfa harvested as hay and evaluated by animal intake and digestion. Crop Sci. 47:2190-2197.

Canadian General Standards Board. 2011. Organic Production Systems, General Principles and Management Standards. CAN/ CGSB-32.310-2006.

CCAC. 2009. Canadian Council on Animal Care Guideline on the Care and Use of Farm Animals in Research, Teaching and Testing. Canadian Council on Animal Care in Science, Ottawa, Ontario, Canada.

Forbes, A. B., C. A. Huckle, and M. J. Gibb. 2004. Impact of eprinomectin on grazing behaviour and performance in dairy cattle with sub-clinical gastrointestinal nematode infections under continuous stocking management. Vet. Parasitol. 125:353-364.

Foster, J. G., W. M. Clapham, D. P. Belesky, M. Labreveux, M. H. Hall, and M. A. Sanderson. 2006. Influence of cultivation site on sesquiterpene lactone composition of forage chicory (Cichorium intybus L.). J. Agric. Food Chem. 54:1772-1778.
Gilleard, J. S., and R. N. Beech. 2007. Population genetics of anthelmintic resistance in parasitic nematodes. Parasitology 134:11331147.

Givens, D. I., E. Owen, and A. T. Adesogan. 2000. Current procedures, future requirements and the need for standardization. Pages 449-474 in Forage Evaluation in Ruminant Nutrition. D. I. Givens, E. Owen, R. F. E. Axford, and H. M. Omed, ed. CABI International, Wallingford, Oxon, UK.

Grabber, J. H. 2008. Mechanical maceration divergently shifts protein degradability in condensed-tannin vs. o-quinone containing conserved forages. Crop Sci. 48:804-813.

Gregorini, P., S. A. Gunter, and P. A. Beck. 2008. Matching plant and animal processes to alter nutrient supply in strip grazed cattle: Timing of herbage and fasting allocation. J. Anim. Sci. 86:10061020.

Gregorini, P., E. M. K. Minnee, W. Griffiths, and J. M. Lee. 2013. Dairy cows increase ingestive mastication and reduce ruminative chewing when grazing chicory and plantain. J. Dairy Sci. 96:7798 7805

Greter, A. M., and T. J. DeVries. 2011. Effect of feeding amount on the feeding and sorting behaviour of lactating dairy cattle. Can. J. Anim. Sci. 91:47-54.

Griffiths, W. M., J. Hodgson, and G. C. Arnold. 2003. The influence of sward canopy structure on foraging decisions by grazing cattle. I. Patch selection. Grass Forage Sci. 58:112-124.

Hall, M. B., W. H. Hoover, J. P. Jennings, and T. K. Miller Webster. 1999. A method for partitioning neutral detergent-soluble carbohydrates. J. Sci. Food Agric. 79:2079-2086.

Horadagoda, A., W. J. Fulkerson, K. S. Nandra, and I. M. Barchia. 2009. Grazing preferences by dairy cows for 14 forage species. Anim. Prod. Sci. 49:586-594.

Jackson, F. S., W. C. McNabb, T. N. Barry, Y. L. Foo, and J. S. Peters. 1996. The condensed tannin content of a range of subtropical and temperate forages and the reactivity of condensed tannin with ribulose-1,5-bis-phosphate carboxylase (rubisco) protein. J. Sci. Food Agric. 72:483-492.

Jones, E. L., and J. E. Roberts. 1991. A note on relationship between palatability and water-soluble carbohydrates concentration in perennial ryegrass. Isr. J. Agric. Res. 30:163-167.

Kirchhof, S., I. Eisner, M. Gierus, and K.-H. Südekum. 2010. Variation in the contents of crude protein fractions of different forage legumes during the spring growth. Grass Forage Sci. 65:376-382.

Licitra, G., T. M. Hernandez, and P. J. Van Soest. 1996. Standardization of procedures for nitrogen fractionation of ruminant feeds. Anim. Feed Sci. Technol. 51:347-358.

Marley, C. L., R. Cook, R. Keatinge, J. Barrett, and N. H. Lampkin. 2003. The effect of birdsfoot trefoil (Lotus corniculatus) and chicory (Cichorium intybus) on parasite intensities and performance of lambs naturally infected with helminth parasites. Vet. Parasitol. 112:147-155.

Marley, C. L., M. D. Fraser, D. A. Davies, M. E. Rees, J. E. Vale, and A. B. Forbes. 2006. The effect of mixed or sequential grazing of cattle and sheep on gastrointestinal parasites and growth rates of weaned lambs. Vet. Parasitol. 142:134-141.

Marten, G. 1978. The animal-plant complex in forage palatability phenomena. J. Anim. Sci. 46:1470-1477.

McLeod, M. N., and B. R. Smith. 1989. Eating and ruminating behaviour in cattle given forages differing in fibre content. Anim. Prod. 48:503-511.

McMahon, L. R., T. A. McAllister, B. P. Berg, W. Majak, S. N. Acharya, J. D. Popp, B. E. Coulman, Y. Wang, and K. J. Cheng. 2000. A review of the effects of forage condensed tanning on ruminal fermentation and bloat in grazing cattle. Can. J. Plant Sci 80:469-485.

Mejía, M., A. Gonzalez-Iglesias, G. S. Diaz-Torga, P. Villafane, N. Formia, C. Libertum, D. Becu-Villalobos, and I. M. Lacau-Mengido. 1999. Effects of continuous ivermectin treatment from birth to puberty on growth and reproduction in dairy heifers. J. Anim. Sci. 77:1329-1334.

Mejía, M. E., A. F. Perri, M. M. Miglierina, N. Formia, D. BecuVillalobos, and M. Lacau-Mengido. 2009. Effect of anthelmintics 
on reproductive performance and first-lactation culling rage in Holstein heifers. Vet. Rec. 165:743-746.

Min, B. R., T. N. Barry, G. T. Attwood, and W. C. McNabb. 2003. The effect of condensed tannins on the nutrition and health of ruminants fed fresh temperate forages: A review. Anim. Feed Sci. Technol. 106:3-19.

Minnee, E. M. K., S. L. Woodward, G. C. Waghorn, and P. G. Laboyrie. 2002. The effect of ensiling forage legumes on condensed tannins. Agronomy N. Z. 32:117-119.

Morin, C., G. Bélanger, G. F. Tremblay, A. Bertrand, Y. Castonguay, R. Drapeau, R. Michaud, R. Berthiaume, and G. Allard. 2011. Diurnal variations of nonstructural carbohydrates and nutritive value in alfalfa. Crop Sci. 51:1297-1306.

Morin, C., G. Bélanger, G. F. Tremblay, A. Bertrand, Y. Castonguay, R. Drapeau, R. Michaud, R. Berthiaume, and G. Allard. 2012. Diurnal variations of nonstructural carbohydrate and nutritive value in timothy. Can. J. Plant Sci. 92:883-887.

Mueller-Harvey, I. 2006. Unravelling the conundrum of tannins in animal nutrition and health. J. Sci. Food Agric. 86:2010-2037.

Müller, C. E., and P. Udén. 2007. Preference of horses for grass conserved as hay, haylage or silage. Anim. Feed Sci. Technol. 132:6678.

Nicholson, J. W. G., E. Charmley, and R. S. Bush. 1992. The effect of supplemental protein source on ammonia levels in rumen fluid and blood and intake of alfalfa silage by beef cattle. Can. J. Anim. Sci. $72: 853-862$.

Nombekela, S. W., M. R. Murphy, H. W. Gonyou, and J. I. Marden. 1994. Dietary preferences in early lactation cows as affected by primary tastes and some common feed flavours. J. Dairy Sci. 77:2393-2399.

Perri, A. F., M. E. Mejía, N. Licoff, L. Lazaro, M. Miglierina, A. Ornstein, D. Becu-Villalobos, and I. M. Lacau-Mengido. 2011. Gastrointestinal parasites presence during the peripartum decreases total milk production in grazing dairy Holstein cows. Vet. Parasitol. 178:311-318.

Pliner, P. 1982. The effect of mere exposure on linking for edible substances. Appetite 3:283-290.

Raggio, G., A. L. Tucker, M. Mongeon, R. Bergeron, and R. Berthiaume. 2010. Effect of cutting management (PM vs. AM) and mac- eration on forage total nonstructural carbohydrates concentration and cattle preference. J. Dairy Sci. 93(E-Suppl. 1):628. (Abstr.)

Ramirez-Restrepo, C. A., and T. N. Barry. 2005. Alternative temperate forages containing secondary compounds for improving sustainable productivity in grazing ruminants. Anim. Feed Sci. Technol. 120:179-201.

Reed, J. D. 1995. Nutritional toxicology of tannins and related polyphenols in forage legumes. J. Anim. Sci. 73:1516-1528.

SAS Institute Inc. 2008. User's guide: Statistics. Version 9.2. 2nd ed. SAS Institute Inc., Cary, NC.

Scharenberg, A., Y. Arrigo, A. Gutzwiller, C. R. Soliva, W. Wyss, M. Kreuzer, and F. Dohme. 2007. Palatability in sheep and in vitro nutritional value of dried and ensiled sainfoin (Onobrychis viciifolia) birdsfoot trefoil (Lotus corniculatus), and chicory (Cichorium intybus). Arch. Anim. Nutr. 61:481-496.

Shepley, E., E. Vasseur, R. Bergeron, A. Villeneuve, and S. Lachance. 2015. Short communication: Birdsfoot trefoil as a preventative treatment for gastrointestinal nematodes in pastured dairy heifers. Can. J. Anim. Sci. http://dx.doi.org/10.4141/CJAS-2014-169.

Smit, H. J., S. Tamminga, and A. Elgersma. 2006. Dairy cattle grazing preference among six cultivars of perennial ryegrass. Agric. J. 98:1213-1220.

Tolkamp, B. J., R. J. Dewhurst, N. C. Friggens, I. Kyriazakis, R. F. Veerkamp, and J. D. Oldham. 1998. Diet choice by dairy cows. 1. Selection of feed protein content during the first half of lactation. J. Dairy Sci. 81:2657-2669.

Van Soest, P. J.. J. D. Robertson, and B. A. Lewis. 1991. Methods for dietary fiber, neutral detergent fiber and non-starch polysaccharide in relation to animal nutrition. J. Dairy Sci. 74:3583-3597.

Vanderstichel, R., I. Dohoo, J. Sanchez, and G. Conboy. 2012. Effects of farm management practices and environmental factors on bulk tank milk antibodies against gastrointestinal nematodes in dairy farms across Canada. Prev. Vet. Med. 104:53-64.

Waghorn, G. C., I. D. Shelton, and W. C. McNabb. 1994. Effects of condensed tannins in Lotus pedunculatus on its nutritive value for sheep. 1. Non-nitrogenous aspects. J. Agric. Sci. 123:99-107.

Waldo, D. R., and N. A. Jorgensen. 1981. Forages for high animal production nutritional factors and effects of conservation. J. Dairy Sci. 64:1207-1229. 